\title{
APLIKASI TEKNOLOGI HIDRO-AKUSTIK GUNA MENINGKATKAN KESELAMATAN PELAYARAN NELAYAN DI TELUK BENOA
}

\author{
Y. Suteja ${ }^{1}$, I.G.N.P. Dirgayusa ${ }^{2}$, Widiastuti ${ }^{3}$ I.Y. Perwira ${ }^{4}$
}

\begin{abstract}
ABSTRAK
Teluk Benoa merupakan muara dari enam sungai yang ada di Provinsi Bali. Adanya proses pendangkalan yang cepat dan tingkat kekeruhan yang tinggi membuat pengamatan batimetri perairan secara visual sulit dilakukan, sehingga batimetri perairan cenderung diketahui berdasarkan pengalaman dan intuisi nelayan. Kondisi ini menyebabkan banyak perahu nelayan yang kandas bahkan rusak parah akibat menabrak dasar perairan, hal ini tentunya membahayakan keselamatan pelayaran yang dilakukan. Salah satu teknologi yang bisa dimanfaatkan untuk mendeteksi batimetri perairan sekaligus untuk menentukan alur pelayaran adalah GPS MAP. Walaupun memiliki banyak kelebihan, pengetahuan masyarakan nelayan di Teluk Benoa tentang teknologi hidro-akustik ini masih sangat kurang. Tujuan dari pengabdian ini adalah memberikan pengetahuan dan cara pengoprasian (pemasangan, penggunaan dan inetrepretasi data) teknologi Hidro-akustik bagi nelayan Teluk Benoa. Khalayak sasaran dalam pengabdaian ini adalah nelayan, kelompok nelayan dan pemiliki kapal di Teluk Benoa. Metode yang digunakan adalah materi, praktek langsung dan diskusi tentang teknologi hidro-akustik. Kegiatan pengabdian masyarakat ini berlangsung baik dan mudah diserap oleh masyrakat karena adanya teori yang diimbangi dengan praktek langsung tentang penggunaan teknologi hidroakustik. Pengabdian ini memberikan informasi tambahan ke nelayan mengenai prinsip dasar alat, tingkat akurasi, kelebihan dan kekurangan, serta tehnik tracking alur pelayaran yang sudah ada. Antusias nelayan terhadap teknologi ini cukup bagus yang ditandai dengan adanya diskusi dua arah selama kegiatan berlangsung
\end{abstract}

Kata kunci : Aplikasi, Hidro-akustik, Nelayan, Teluk Benoa

\begin{abstract}
Benoa Bay is the estuary of six rivers in the Bali Province. The high sedimentation process and turbidity level makes observing the bathymetry visually was difficult, so that the bathymetry of the waters tends to be known based on the experience of fishermen. This condition causes many fishing boats crashing the bottom and endangering the safety of the voyages. One of the technologies that can be used to detect bathymetry of waters as well as to determine the flow of shipping is GPS MAP. Even though they have many advantages, the knowledge of the fishermen in Benoa Bay about this hydro-acoustic technology was still lack. The purpose of this service is to provide knowledge and operating procedure (installing, using and interpreting data) hydro-acoustic technology for Benoa Bay fishermen. The target audience for this service is fishermen,
\end{abstract}

\footnotetext{
${ }^{1}$ Staf PengajarJurusan Ilmu Kelautan Fakultas Kelautan dan Perikanan Universitas Udayana, yuliantosuteja@unud.ac.id

${ }^{2}$ Staf PengajarJurusan Ilmu Kelautan Fakultas Kelautan dan Perikanan Universitas Udayana, ignpdirgayusa@gmail.com

${ }^{3}$ Staf PengajarJurusan Ilmu Kelautan Fakultas Kelautan dan Perikanan Universitas Udayana, widiastutikarim@unud.ac.id

${ }^{4}$ Staf PengajarJurusan Manajemen Sumberdaya Perairan Fakultas Kelautan dan Perikanan Universitas Udayana, imayudha@gmail.com
} 
fishing groups and boat owners in Benoa Bay. The method used was lecture, direct practice and discussion of hydro-acoustic technology. These community service activities was running well and easily absorbed by the community because of the theory that is balanced with direct practice of the use of hydro-acoustic technology. This community service provides additional information to fishermen about the basic principles of the equipment, the level of accuracy, strengths and weaknesses, as well as the tracking technique of existing shipping lines. The enthusiasm of fishermen for this technology was quite good, which was marked by twoway discussions during the activity.

Keywords: Aplication Application, Benoa Bay, Fishermen, Hydro-acoustic

\section{PENDAHULUAN}

Teluk Benoa merupakan salah satu teluk di wilayah Provinsi Bali yang merupakan tempat bermuaranya enam sungai yaitu sungai Bualu, Sama, Mati, Badung, Loloan dan Buaji. Selain berfungsi membawa air tawar dari daerah hulu ke daerah hilir, sungai-sungai ini ternyata membawa bahan pencemaran yang sangat tinggi ke perairan Teluk Benoa (Suteja dan Purwiyanto (2018), bahkan pencemar ini sudah melebihi baku mutu yang telah ditetapkan oleh pemerintah dalam Peraturan Gubernur Bali Nomor 16 Tahun 2016 (Rahayu et al., 2018; Suteja and Dirgayusa, 2018). Salah satu pencemaran yang dibawa oleh aliran sungai ini adalah logam berat kromium (Suteja dan Dirgayusa, 2018) dan Total Padatan Tersuspensi (Total Suspended Solid/TSS) yang dihasilkan dari proses abrasi didaerah pertanian dan/atau di daerah aliran sungai (DAS). Pengikisan yang cukup tinggi ini mengakibatkan konsetrasi TSS dan kekeruhan air di daerah Teluk Benoa sangat tinggi (Hendrawan et al. 2016) dan mencapai kosentrasi maksimal saat musim hujan (Risuana et al. 2017). Tingginya TSS di Teluk Benoa berdampak kepada proses proses percepatan pendangkalan perairan yang akan berpengaruh terhadap batimetri. Hasil simulasi numerik yang dilakukan oleh Maharta et al. (2019) menunjukkan bahwa rata-rata Teluk Benoa mengalami laju sedimentasi sebesar 0,57 $\mathrm{kg} / \mathrm{m} 2 /$ hari dengan pendangkalan sekitar $0,23 \mathrm{~m} /$ tahun.

Selain berfungsi secara ekologis sebagai tenpat tinggal bagi ikan (proses pemijahan, pembesaran, dan asuhan) dan sebagai tempat hidup beberapa ekosistem laut (mangrove, lamun dan terumbu karang), Teluk Benoa juga memiliki fungsi secara ekonomis untuk dimanfaatkan oleh warga sekitar sebagai daerah tangkapan ikan, wisata air (jetski, banan boat dll) serta jalur pelayaran untuk menuju Selat Lombok ataupun Selat Badung. Adanya proses pendangkalan yang sangat cepat dan tingkat kekeruhan yang tinggi membuat pengamatan kedalaman (batimetri) perairan secara visual sangat sulit dilakukan, sehingga batimetri perairan cenderung diketahui berdasarkan pengalaman dan intuisi nelayan. Kondisi ini menyebabkan banyak perahu nelayan yang kandas bahkan dibeberapa kasus mengakibatkan kerusakan yang parah akibat menabrak dasar perairan. Hal ini tentunya akan sangat membahayakan bagi keselamatan pelayaran yang dilakukan oleh nelayan maupun warga yang beraktifitas di Teluk Benoa.

Salah satu teknologi yang bisa dimanfaatkan untuk mendeteksi batimetri perairan sekaligus untuk menentukan alur pelayaran adalah GPS MAP. GPS MAP merupakan aplikasi dari teknologi HidroAkustik yang berkerja berdasarkan prinsip perambatan gelombang suara dalam air. Teknologi Hidro-Akustik ini mampu memberikan informasi yang cukup detail tentang batimetri perairan, bahkan bisa memperbaharui data batimetri dalam hitungan detik. Selain itu teknologi ini dilengkapi dengan fasilitas Global Positioning System (GPS) yang berfungsi untuk mengatahui posisi koordinat kapal. Fasilitas GPS ini bisa digunakan untuk melakukan proses marking (menandai) daerah-daerah dangkal yang berbahaya terhadap keamanan pelayaran. Selain kelebihan di atas, teknologi hidro-akustik ini memberikan data yang bersifat real time, tidak menganggu ekosistem, akurasi cukup tinggi dan harga yang relative murah. Walaupun memiliki banyak kelebihan, pengetahuan masyarakan nelayan di Teluk Benoa tentang teknologi hidro-akustik ini cenderung tidak ada atau bahkan tidak mengenalnya sama sekali. Pengetahuan ini meliputi prinsip dasar, cara 
pemasangan di perahu, tehnik pengoprasian dan interpretasi data teknologi hidro-akustik yang baik dan benar. Adanya perpaduan antara kearifan lokal dan teknologi hidro-akustik diharapkan dapat memberikan informasi tentang alur pelayaran yang aman bagi nelayan sehingga dapat meningkatkan keselamatan pelayaran di Teluk Benoa. Pelatihan penggunaan fishfinder pernah diaplikasikan di nelayan kedongan (Suteja et al., 2018), namun penggunaan teknologi Hidroakustik untuk pendeteksi kedalaman belum pernah dilakukan.

Berdasarkan penjelasan analisis situasi tentang nelayan di Teluk Benoa di atas, dapat dirumuskan permasalahan bahwa pengetahuan nelayan tentang teknologi hidro-akustik ini masih belum terlalu banyak. Pengetahuin ini meliputi prinsip dasar, cara pemasangan di perahu, tehnik pengoprasian, dan interpretasi data teknologi hidro-akustik yang baik dan benar. Tujuan dari pengabdian ini adalah Memberikan tambahan khazanah ilmu pengetahuan kepada nelayan Teluk Benoa tentang teknologi hidro-akustik terutama mengenai prisip kerja, pelatihan tentang cara pengoprasian teknologi hidro-akustik yang meliputi tehnik pemasangan di perahu, pengoprasian alat, dan interpretasi data yang baik dan benar.

\section{METODE PELAKSANAAN}

Metode dalam pengabdian aplikasi teknologi Hidro-akustik ini adalah ceramah yang bersifat person to person, praktik langsung dan tanya jawab. Adapun masyarakat yang menjadi khalayak sasaran adalah nelayan, kelompok nelayan dan pemiliki kapal yang secara langsung ataupun tidak langsung ada diwilayah Teluk Benoa.

\section{HASIL DAN PEMBAHASAN}

Kegiatan pengabdian dilaksanakan oleh tenaga pengajar dan mahasiswa/i Fakultas Kelautan dan Perikanan, Universitas Udayana yang berjudul "Aplikasi Teknologi Hidro-Akustik Guna Meningkatkan Keselamatan Pelayaran Nelayan di Teluk Benoa" mengalami perubahan metode penyampain. Pada awalnya, penyampaian materi yang direncanakan adalah dengan metode ceramah di depan perwakilan kelompok nelayan, akan tetapi karena kesibukan nelayan dan susahnya mengatur waktu tiap nelayan untuk kumpul maka dilakukan metode person to person dengan cara oral yang bertujuan agar kegiatan lebih fokus dan memiliki waktu yang lebih fleksibel. Pada kegiatan ini diundang dan dilatih masing-masing satu orang perwakilan dari tiap kelompok nelayan yang sering melakukan aktifitas di Teluk Benoa.

Pelaksanaan kegiatan program udayana mengabdi ini dilakukan pada tangal 2 dan 10 Juli 2019 pada pukul 09.00 - 13.00 WITA saat kondisi air pasang. Kondisi pasang ini dipilih dengan pertimbangan agar kondisi teluk menjadi lebih dalam dan kapal nelayan lebih mudah bergerak di perairan untuk mendeteksi kedalaman air. Pada pukul 9.00 sampa 10.00 WITA dilakukan persiapan alat-alat untuk mengkegiatan pengabdian berupa penyiapan tongkat tranducer, aki dan pemasangan alat di perahu. Proses ini dilakukan oleh team pengabdian (termasuk narasumber) yang di dukung oleh mahasiswa dan nelayan yang akan mengikuti training tentang teknologi hidro-akustik (Error! Reference source not found.3.1). Pada proses pemasangan alat ini lebih banyak melibatkan nelayan dengan bantuan arahan dari team pengabdian, hal ini dimaksudkan agar nelayan lebih faham tentang apa yang akan di lakukan (learning by doing). Pada saat proses pemasanagan teknologi hidro-akustik ini, narasumber sekaligus menjelaskan tentang alasan-asalan penempatan alat di perahu, posisi antena, posisi tranducer, dan kondisi aki.

\section{4 | BULETIN UDAYANA MENGABDI}




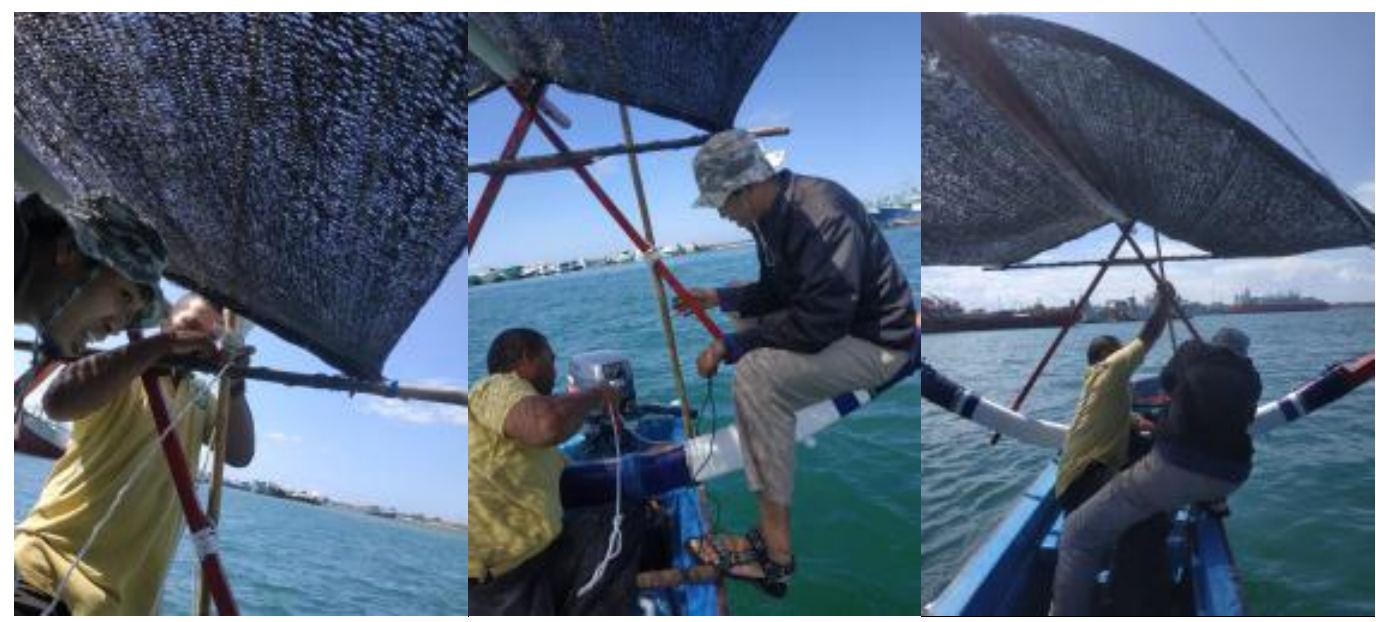

Gambar 3.1. Proses pemasangan antena dan tranducer oleh nelayan dibantu team Program Udayana Mengabdi

Setelah proses rangkaian alat selesai maka dilanjutkan dengan proses pengecekan alat teknologi hidro-akustik, apakah alat sudah berfungsi dengan baik atau tikak. Proses ini dilakukan dengan mendengarkan bunyi ping (sinyal) dari tranducer secara manual. Setelah alat siap, maka alat diikat dan dilakukan pengukuran batimetri. Pada saat alat mengukur batimetri di Teluk Benoa, team pengabdian menjelaskan tentang tehnik pembacaaan data yang tertera pada layar (Error! Reference source not found.3.2). Pada proses ini dijelaskan bagaimana cara membaca kedalaman air dan cara mengetahui alur pelayaran yang aman berdasarkan batimetri yang di dapat dari alat.

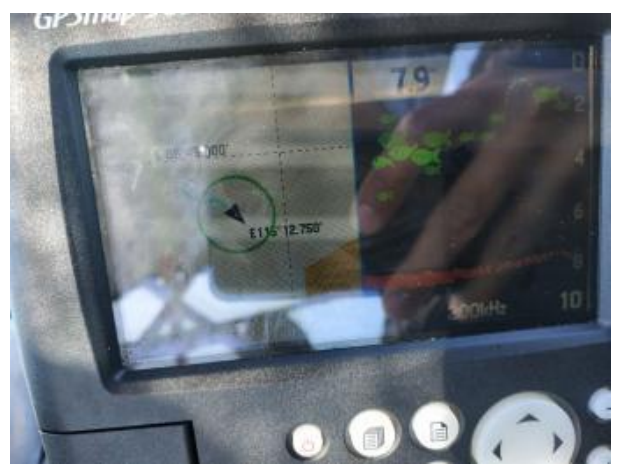

Gambar 3.2. Tampilan data teknologi hidro-akustik

Pada saat melakuan pemeruman batimetri disisipkan materi-materi tentang teknologi hidro-akustik yang berisi tentang varian dari teknologi hidroakustik baik yang bersifat singlebeam dengan harga yang lebih murah dan multibeam yang sering digunakan pada kapal besar dengan harga yang relative lebih mahal. Selain itu juga dijelaskan tentang bagian-bagian dan fungsi dari masing alat yang ada. Materi ini diberikan agar nelayan mengetahui bagian mana yang sensitive agar alat yang dipakai bertahan lama dan tidak mudah rusak, termasuk dijelaskan bagian mana yang tahan air dan tidak. Setelah itu dijelaskan tentang tingkatan frekuensi suara yang dipergunakan dan kapan kapan harus menggunakan tingkat suara dengan frekuensi tinggi dan rendah. Selain itu team pengabdian juga memberikan penjelasan tambahan mengenai fungsi lain dari teknologi hidro-akustik yang dapat dipergunakan untuk mengetahui ada tidaknya ikan (fishfinder) dan posisi kedalaman ikan berdasarkan tampilan pada layar. Proses transfer pengetahuan dasar tentang fishfinder berlangsung sangat lancar dan baik yang dibuktikan dengan keseriusan peserta memperhatikan praktek dan teori yang disampaikan oleh team pengabdian (Error! Reference source not found.3.3). 

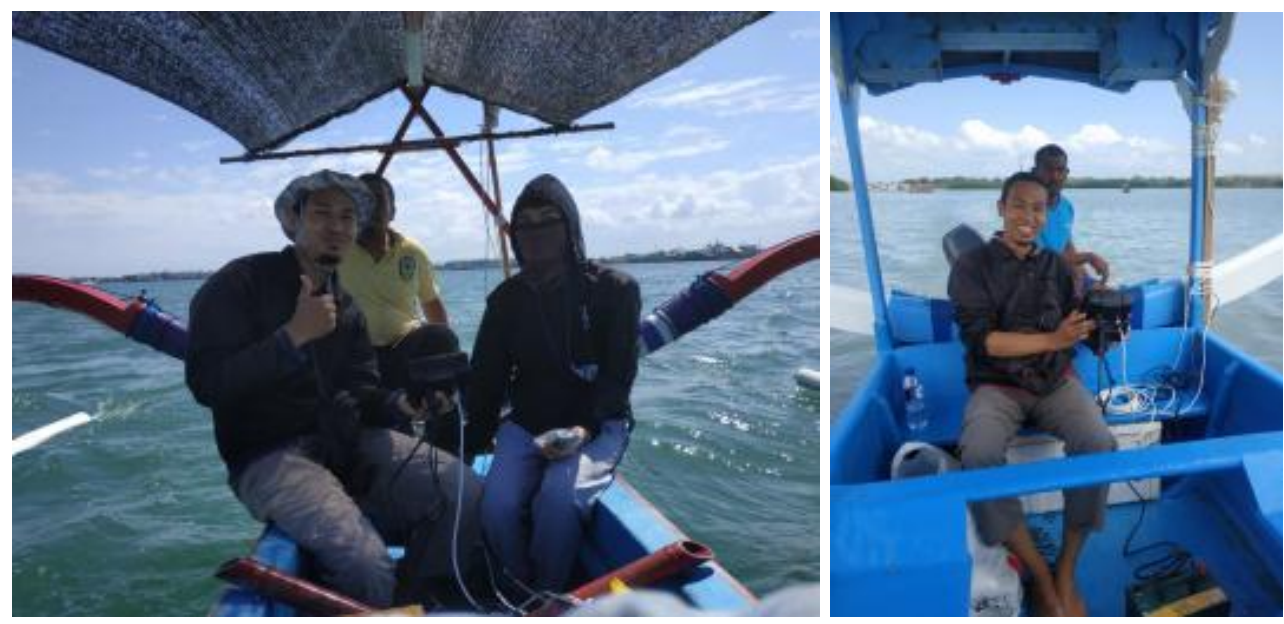

Gambar 3.3. Proses pemaparan materi yang dirangkaikan dengan diskusi tentang teknologi hidro-akustik

Pada proses diskusi nelayan banyak mengkritisi tentang akurasi, kelebihan dan kekurangan teknologi hidro-akustik. Nelayan juga sangat antusias terutama mengenai materi cara membaca data yang ada di layar monitor, hal ini dibuktikan diskusi dua arah yang aktif tentang arti symbol yang ada di layar termasuk yang terkait dengan teknis-teknis jika ada masalah yang terjadi. Nelayan yang ada di Teluk Benoa mengeluhkan tentang proses pendangkalan yang terjadi di sehingga sering kapal yang kandas (Gambar 3.4). Pada saat kegiatan pengabdian dilakukan, kapal nelayan yang dipakai kandas karena pendangkalan dan air yang sudah mulai surut. Selain itu adanya proses pengerukan kolam pelabuhan yang sedang berlangsung di Teluk Benoa menyebabkan nelayan kurang mengetahui batimetri sekitar pelabuhan saat ini. Sebagai informasi, bahwa semua peserta yang ikut pelatihan aplikasi teknologi hidro-akustik ini mengaku pernah melihat dan menggunakan teknologi ini terutama untuk kegiatan memancing, namun banyak yang kurang memahami tentang informasi yang disajikan pada monitor. Semua pertanyaan yang disampaikan oleh nelayan dapat dijawab dengan baik oleh team pengabdian sehingga tidak ada pertanyaan lagi.
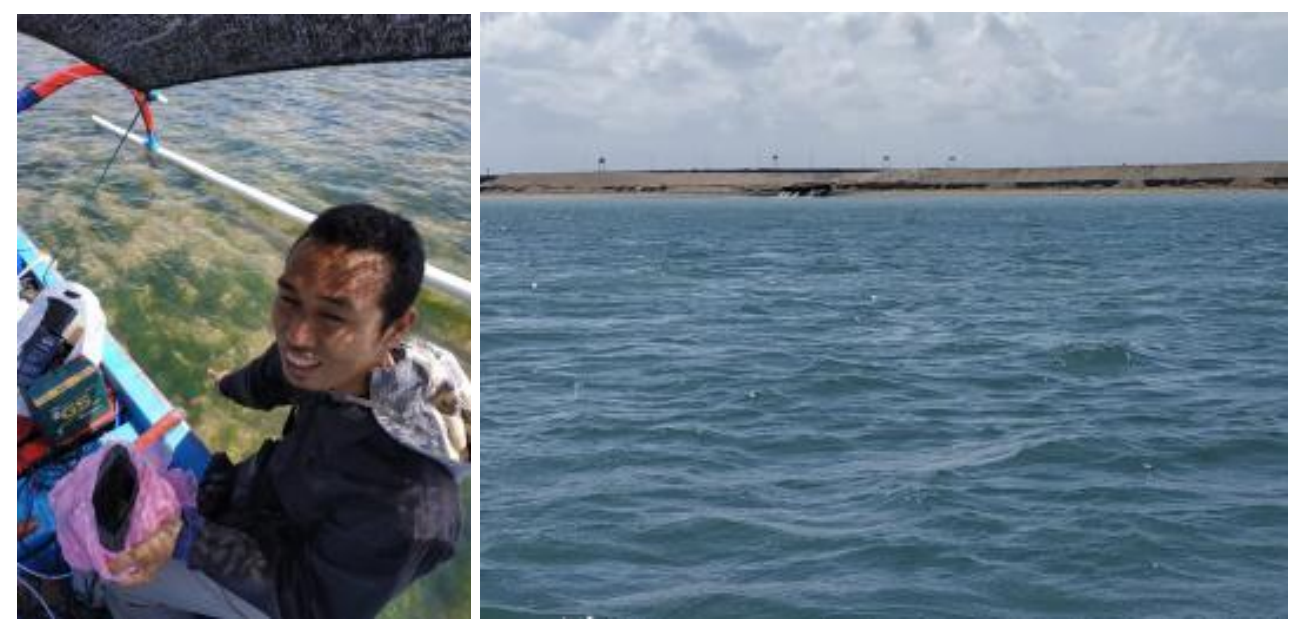

Gambar 3.4. Kondisi dasar perairan (kiri) dan tumpukan sedimen hasil pengerukan kolam pelabuhan di Teluk Benoa (kanan) 


\section{KESIMPULAN DAN SARAN}

\subsection{Kesimpulan}

Kegiatan Program Udayana Mengabdi yang mengangkat tema teknologi hidro-akustik untuk keselamatan pelayaran nelayan di Teluk Benoa berlangsung lancar dan baik. Pengabdian ini berhasil mentransfer informasi tambahan teknologi hidroakustik dan tehnik penggunaan alat yang baik dan benar. Pengabdian ini menunjukkan nelayan memiliki atusias yang tinggi yang ditunjukkan oleha ditunjukkan oleh adanya interaksi dua arah saat pengabdian berjalan.

\subsection{Saran}

Dari pengabdian yang dilakukan ini nelayan mengharapkan perhatian Pemerintah Daerah Kabupaten Badung, Pemerintah Provinsi Bali dan/atau Universitas Udayana untuk memberikan bantuan teknologi hidro-akustik agar ilmu yang didapatkan tidak sia-sia dan bisa dipraktekkan langsung dalam kegiatan sehari-hari.

\section{UCAPAN TERIMAKASIH}

Terima kasih kami ucapkan ke Universitas Udayana yang membiaya kegiatan ini melalui Program Udayana Mengabdi tahun 2019. Penulis menyampaiakan penghargaan yang sebesar-besarnya kepada nelayan di Teluk Benoa dan mahasiswa serta pihak-pihak yang yang telah memberikan sumbangsih untuk terlaksananya program pengabdian Universitas Udayana ini.

\section{DAFTAR PUSTAKA}

Hendrawan, I.G., D. Uniluha, dan I.P.R.F. Maharta (2016). Karakteristik Total Padatan Tersuspensi (Total Suspended Solid) Dan Kekeruhan (Turbidity) Secara Vertikal Di Perairan Teluk Benoa, Bali. Journal of Marine and Aquatic Sciences. Vol 2:1, pp. 29-33.

Maharta, I.P.R.F., I.G. Hendrawan, dan Y. Suteja (2019). Prediksi Laju Sedimentasi di Perairan Teluk Benoa Menggunakan Pemodelan Numerik. Journal of Marine and Aquatic Sciences. Vol 5:1, pp. 44-54.

Rahayu, N.W.S.T., I.G. Hendrawan, dan Y. Suteja (2018). Distribusi Nitrat dan Fosfat Secara Spasial dan Temporal Saat Musim Barat Di Permukaan Perairan Teluk Benoa, Bali. Journal of Marine and Aquatic Sciences. Vol 4:1, pp. 1-13.

Risuana, I.G.S., I.G. Hendrawan, dan Y. Suteja (2017). Distribusi Spasial Total Padatan Tersuspensi Puncak Musim Hujan Di Permukaan Perairan Teluk Benoa, Bali. Journal of Marine and Aquatic Sciences. Vol 3:2, pp. 223-232.

Suteja, Y., dan A.I.S. Purwiyanto (2018). Nitrate and Phosphate from Rivers as Mitigation of Eutrophication in Benoa Bay, Bali-Indonesia. First International Conference on Maritime Sciences and Advance Technology. IOP Conference Series: Earth and Environmental Science Vol. 162 No. 1, p. 012021).

Suteja, Y., dan I.G.N.P. Dirgayusa. Suteja, Y., \& Dirgayusa, I. G. N. P. (2018). Bioaccumulation and translocation of chromium on crabs and mangroves in Mati River estuary, Bali, Indonesia. Aquaculture, Aquarium, Conservation \& Legislation. Vol 11:2, pp. 469-475

Suteja, Y., and Dirgayusa, I.G.N.P. (2018). Detection of Eutrophication In Benoa Bay-Bali. Omni-Akuatika, Vol 14(3), pp. 18-25.

Suteja, Y., I.G.N.P. Dirgayusa, Widiastuti, dan I.D.N.N., Putra (2018). Pelatihan Penggunaan Fishfinder Bagi Nelayan Kedonganan Guna Meningkatan Produksi Perikanan. Buletin Udayana Mengabdi. Vol 18:1, pp. 143-148. 